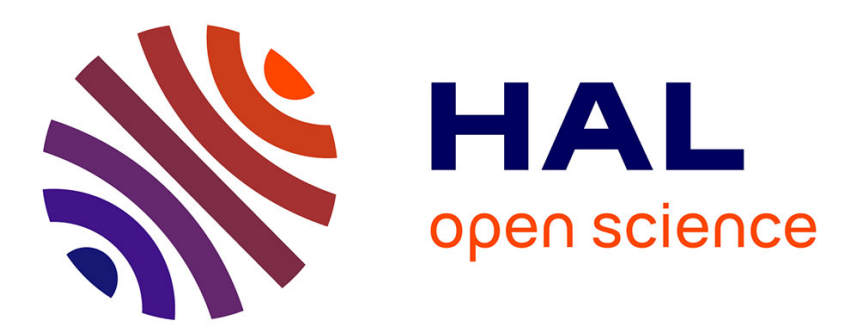

\title{
Treatment of SMC Composite Waste for Recycling as Reinforcing Fillers in Thermoplastics
}

\author{
Didier Perrin, Eric Leroy, Laurent Clerc, Anne Bergeret, José-Marie
}

Lopez-Cuesta

\section{- To cite this version:}

Didier Perrin, Eric Leroy, Laurent Clerc, Anne Bergeret, José-Marie Lopez-Cuesta. Treatment of SMC Composite Waste for Recycling as Reinforcing Fillers in Thermoplastics. Macromolecular Symposia, 2005, 221 (1), pp.227-236. 10.1002/masy.200550323 . hal-02536551

\section{HAL Id: hal-02536551 \\ https://hal.mines-ales.fr/hal-02536551}

Submitted on 17 Apr 2020

HAL is a multi-disciplinary open access archive for the deposit and dissemination of scientific research documents, whether they are published or not. The documents may come from teaching and research institutions in France or abroad, or from public or private research centers.
L'archive ouverte pluridisciplinaire HAL, est destinée au dépôt et à la diffusion de documents scientifiques de niveau recherche, publiés ou non, émanant des établissements d'enseignement et de recherche français ou étrangers, des laboratoires publics ou privés. 


\title{
Treatment of SMC Composite Waste for Recycling as Reinforcing Fillers in Thermoplastics
}

\author{
Didier Perrin, Eric Leroy, * Laurent Clerc, Anne Bergeret, José-Marie Lopez-Cuesta \\ Centre des Matériaux de Grande Diffusion (CMGD), Ecole des Mines d'Alès, \\ 6 avenue de Clavières, 30319 Alès Cedex, France \\ Fax: (+33) 4667853 65; E-mail: eric.leroy@ema.fr
}

\begin{abstract}
Summary: Needs for recycling thermoset composite materials are considerably increasing. Unfortunately, such materials are particularly difficult to recycle due to their crosslinked nature. In this paper, we focus on the case of Sheet Moulding Compounds (SMC), which consist of an unsaturated polyester filled with glass fibres and calcium carbonate. We consider the possibilities of mechanical treatments allowing to obtain ground fractions that could be used as fillers for the reinforcement of thermoplastics. Two processes are described and compared with an existing industrial one. Finally, optimised fractions of SMC waste are introduced into polypropylene, leading to promising results in term of mechanical properties.
\end{abstract}

Keywords: composites; fibre; grinding; recycling; SMC

\section{Introduction}

Thermosetting Polyester / Glass Fibre / Calcium carbonate composites, such as Sheet Moulding Compounds (SMC) ${ }^{[1]}$, are high strength-to-weight ratio and low cost materials currently used in large series sectors such as automotive or electrical industry. Nevertheless, these composite materials are difficult to recycle ${ }^{[2]}$. This constitutes an important drawback for these two industrial sectors, which are subjected to recent and future European regulations asking for high material recyclability. At the same time, landfilling costs and regulations are becoming more and more incompatible with the current $10^{6}$ tons per year European consumption of these materials. Consequently, there exists an urgent need for developing adapted recycling techniques ${ }^{[3,4]}$.

The main obstacle to recyclability is coming from the crosslinked nature of the thermoset matrix, which makes its melting impossible, so that conventional technologies used for thermoplastics are not applicable. In the particular case of SMC composites, which composition consisted of 25 $\mathrm{wt} \%$ of crosslinked polyester resin, reinforced by $25 \mathrm{wt} \%$ glass fibres and filled with $50 \mathrm{wt} \%$ 
calcium carbonate, various recycling or valorisation strategies has been proposed : one way for SMC recycling is nowadays incineration with energy recovery, in which the organic matrix is burned, the inorganic residue being either landfilled or used as low grade aggregates. Technical investigations for incineration on this time are the more economically viable recycling solution. Chemical solvolysis of the matrix ${ }^{[5]}$, or its sublimation in a fluidised bed process, ${ }^{[2,3]}$ seem to become more promising techniques but they are still at the research stage. Mechanical recycling seems to be at this moment the only strategy that has reached industrial applications ${ }^{[4,6]}$. This technique is based on granulation and comminution of the composite material, possibly followed by a sieving process. The obtained fractions (fibres, powder) could be used for a variety of applications, depending on the particle size and glass fibre content : as fine powders (below $300-$ $400 \mu \mathrm{m}$ ) could be for example used as fillers in thermoset compounds such as Bulk Moulding Compound (BMC), and long fibres (above $10 \mathrm{~mm}$ ) in civil engineering materials $\mathrm{s}^{[7,9-10]}$, medium size fibres (about $1 \mathrm{~mm}$ ) are recyclable in thermoplastics ${ }^{[11,12]}$.

The present work is focused on this last promising ${ }^{[6-8]}$ application, with the aim to develop a process allowing to obtain ground SMC fractions with optimised characteristics for their introduction as reinforcing fillers in thermoplastics. Two different treatment strategies, starting from SMC production waste are described and compared : the first strategy consists of a pure mechanical grinding where the compound is reduced in powder fractions, whereas the second strategy is a mixed process in which shredding, is followed by a partial dissolution of calcium carbonate using an acid solution. The results of these two approaches are compared in terms of process efficiency, glass fibre content of the obtained SMC ground fraction and glass fibre size distribution. These two last characteristics are of particular importance for the reinforcement of thermoplastics. Finally, the optimised selected fraction will be introduced in polypropylene (PP). The mechanical properties of the resulting composite will be compared to those of a commercial recycled SMC / PP composite and of a unrecycled glass fibres / PP composite.

\section{Experimental}

\section{Materials :}

$500 \times 500 \times 4 \mathrm{~mm}^{3} \mathrm{SMC}$ composite panels provided by Saint Gobain Vetrotex International company (Chambéry, France) were moulded by Compositec SA (Le Bourget du Lac, France). 
The resulting samples constitute model SMC production waste. Commercial short glass fibres (unrecycled fibres of average length $4,5 \mathrm{~mm}$ and diameter $15 \mu \mathrm{m}$ ), with a surface treatment compatible for an introduction into polypropylene matrix (PP) were also supplied by Saint Gobain Vetrotex International. Post-consumer commercial SMC ground fraction (T401) optimised for recycling as thermoplastic filler/reinforcement, was supplied by MCR (Tournon, France) as grey aggregates (about 0.5 and $1 \mathrm{~cm}$ in diameter) and used as reference.

Thermoplastic matrix used for composite manufacturing was supplied by Appryl under the trade name $3150 \mathrm{MN} 5$, and consisted in mixture of polypropylene homopolymer (84 wt \%) and (propylene-co-ethylene) 50/50 wt \% copolymer (16 wt \%).

\section{Preparation of SMC ground fractions}

The model SMC production waste sheets were first manually cut and conditioned into smaller parts $\left(50 \times 50 \times 4 \mathrm{~mm}^{3}\right)$, which were then treated by one of the two processes described on Figure 1, leading to two different filler fractions : $\mathrm{SMC}_{1}^{\text {mod }}$ and $\mathrm{SMC}_{2}^{\text {mod }}{ }_{2}$.

The filler $\mathrm{SMC}^{\mathrm{mod}}$, was obtained from a pure mechanical grinding. The SMC pieces were ground using a Rotoplex-Alpine Rotary Cutter Mill working at a $1500 \mathrm{rpm}$ and using a three steps procedure (Figure 1). Each step consisted in grinding the material during $25 \mathrm{~min}$, the ground fraction passing through a grid being ground again in the next step. Three different grids were used, with progressively reduced hole diameters ( $12 \mathrm{~mm}$ for step $1,6 \mathrm{~mm}$ for step 2 , and finally 4 $\mathrm{mm}$ for the step 3).

The filler $\mathrm{SMC}^{\mathrm{mod}}{ }_{2}$ was obtained from a mixed process consisting in two steps. The SMC pieces were first ground during 25 minutes at a $1500 \mathrm{rpm}$ using the same Rotoplex-Alpine Rotary Cutter Mill, with a grid of $12 \mathrm{~mm}$. The passing ground fraction was then introduced in a $\mathrm{H}_{3} \mathrm{PO}_{4}$ buffer solution with strong agitation in order to partially dissolve the calcium carbonate. After that, the filler was filtered and dried. The objective of this second treatment was to obtain the highest fibre fraction and fibre length in the final filler. Two experimental devices were used to optimise the acid concentration, the agitation time and the conditions of sieving. So, the following dissolution conditions were obtained : $100 \mathrm{~g}$ of shredded SMC was dissolved at room temperature into a $\mathrm{H}_{3} \mathrm{PO}_{4}$ buffer solution $(0.3 \mathrm{M}, \mathrm{pH} 1.9,5 \mathrm{l})$. The stirring time and the rotative speed of the propeller agitator were respectively of $60 \mathrm{~min}$ and $1980 \mathrm{rpm}$. The partially dissolved fraction was then filtered and dried for $3 \mathrm{~h}$ at $80^{\circ} \mathrm{C}$ and $7 \mathrm{~h}$ at $60^{\circ} \mathrm{C}$. 


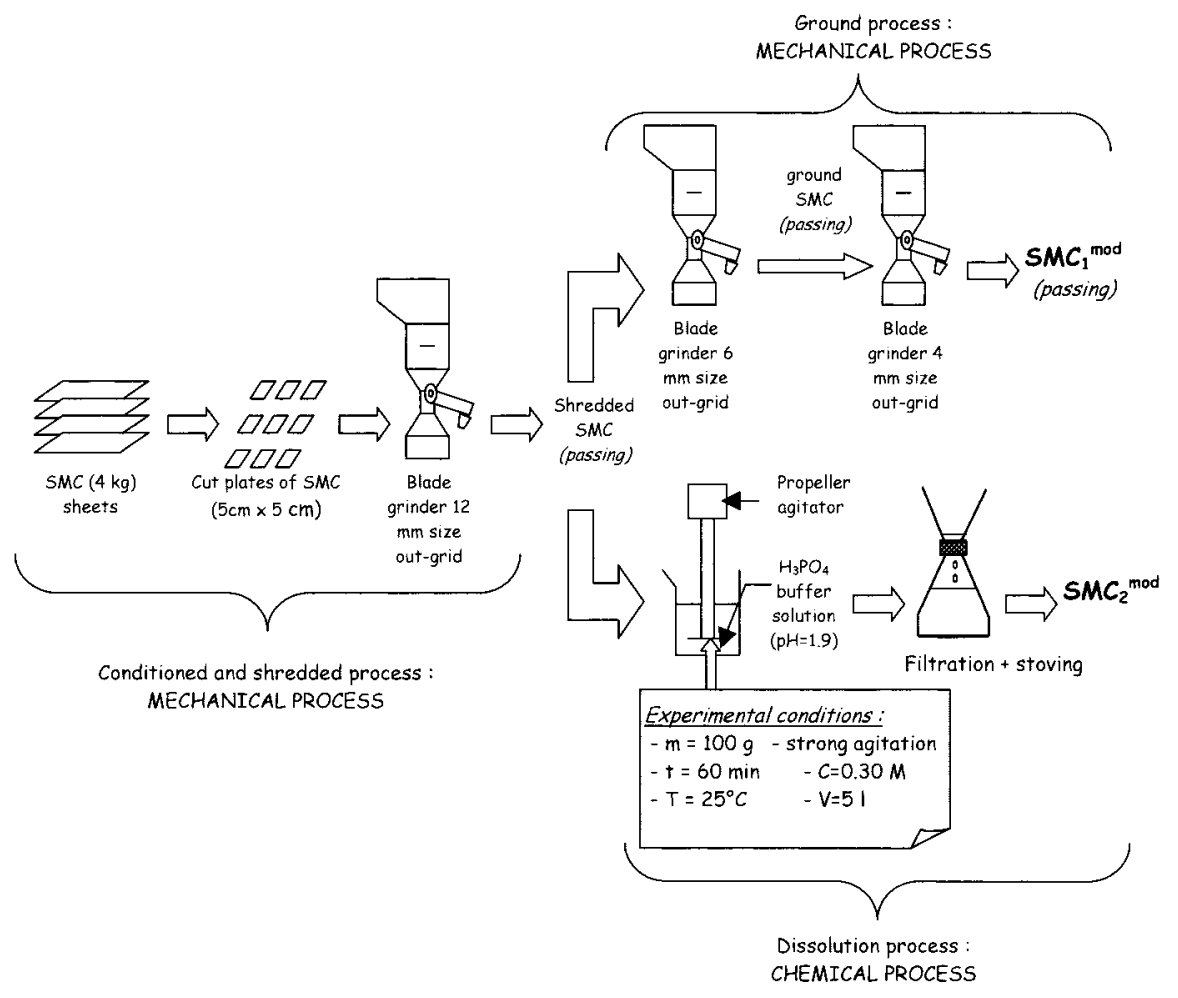

Figure 1. Preparation of fillers from SMC production.

\section{Characterisation of the different recycled fractions $\left(\mathrm{SMC}^{\mathrm{mod}}{ }_{1}, \mathrm{SMC}^{\mathrm{mod}}{ }_{2}, \mathrm{T401}\right)$}

$\mathrm{SMC}_{1}^{\bmod }{ }_{1}, \mathrm{SMC}^{\bmod }{ }_{2}$ and T401 samples were first observed by Scanning Electron Microscopy (JEOL JSM 35CF) in order to analyse the morphology of the samples. Then, the composition of these recycled fractions and of the initial SMC panels was determined as follows :

(i) The organic fraction, mainly composed of the polyester resin matrix, was first measured by weight loss after pyrolysis at $550^{\circ} \mathrm{C}$ for $180 \mathrm{~min}$;

(ii) $\mathrm{CaCO}_{3}$ amount was then measured by calcimetry. This technique consisted in the dissolution of about 1- $2 \mathrm{~g}$ of $\mathrm{SMC}$ fraction in a $\mathrm{HCl}$ solution and the measurement of $\mathrm{CO}_{2}$ volume 
evolved from the reaction with $\mathrm{CaCO}_{3}$. For experiments which were investigated in standard temperature and pressure conditions, the amount of calcium carbonate present in the filler can be determined by the following equation (1) :

$$
\% \mathrm{CaCO}_{3}=\frac{100 \cdot M_{\mathrm{CaCO}_{3}} \cdot V_{\mathrm{CO}_{2}}}{24040 . m_{S M C}}
$$

where $m_{S M C}$ is the SMC amount, $V_{\mathrm{CO} 2}$ the $\mathrm{CO}_{2}$ volume evolved and $M_{\mathrm{CaCO} 3}$ the molar mass of $\mathrm{CaCO}_{3}$.

(iii) Finally, the remaining glass fibre fraction was calculated by mass balance. The process efficiency is determined by the following equation (2) :

$$
R_{m}=\frac{m_{p}}{\sum_{p} m_{p}+\sum_{r} m_{r}+\sum_{p e r} m_{p e r}}
$$

where $m_{p}$ is the mass of passing elements, $m_{r}$ the mass of oversize elements and $m_{p e r}$ the mass of the overall wastes.

Fibre length distribution was determined both before and after composite processing for all the recycled fractions $\left(\mathrm{SMC}_{1}^{\mathrm{mod}}, \mathrm{SMC}^{\mathrm{mod}}{ }_{2}\right.$ and $\left.\mathrm{T} 401\right)$ and for the commercial short glass fibres after extrusion. In all cases, the material was first pyrolised and put in contact with $\mathrm{HCl}$ in order to eliminate organic and calcium carbonate residues. About $1 \mathrm{mg}$ of the remaining fibres was dispersed into water to a roasted glass of porosity 4 (hole diameter of $5-15 \mu \mathrm{m}$ ) which prevented the crossing of fibres through the filter with glass plates on the bottom. The system was then put under vacuum in order to evaporate the water, so that the fibres would cast onto the glass plates deposited into the roasted glass. This procedure allowed to obtain well separated fibres, without using any solvent as a difference with techniques described in litterature ${ }^{[8,15]}$.

Another advantage of this method is that no shear is applied on the fibres which are relatively brittle in comparison with another technique, in which fibres are put between two glass plates with polyethylene glycol and dispersed by shear ${ }^{[13]}$.

For each sample, 10 glass plates with dispersed fibres were prepared. 30 photographs per sample observed through Wild Heerbrugg M8 binocular were taken with a high resolution Sony Iris CCD cine-camera to have a 800 fibres population ${ }^{[16-19]}$. Analogical signal to numeric one conversion was carried out by a IC-PCI numerisation card so that images size of $768 \times 572$ pixels were 
obtained. Fibres length distribution was then obtained by a semi-automatic images analysis system based on Optimas software. Number average length $L_{n}$, length average length $L_{l}$ and dispersity were then calculated using equations ( 3 to 5 ).

$$
\begin{gathered}
L_{n}=\frac{\sum_{i} \frac{1}{P_{i}} L_{i}}{\sum_{i} \frac{1}{P_{i}}} \\
L_{l}=\frac{\sum_{i} \frac{1}{P_{i}} L_{i}^{2}}{\sum_{i} \frac{1}{P_{i}} L_{i}} \\
D=\frac{L_{l}-L_{n}}{L_{n}}
\end{gathered}
$$

\section{Composite processing :}

The different PP composites studied are listed on Table 1. The filler contents were chosen in order to have the same final $20 \mathrm{wt} \%$ glass fibre content to the composite. It can be observed that it was necessary to introduce $47 \mathrm{wt} \%$ of SMC ${ }^{\bmod }{ }_{1}$ or $\mathrm{SMC}^{\bmod }{ }_{2}$ fractions in order to obtain a final filler content of $20 \mathrm{wt} \%$ so that it would be difficult to process composites systems with higher fibre contents. A twin screw extruder was used to compound the various fibrous samples into PP (Clextral BC $21,200^{\circ} \mathrm{C}, 350 \mathrm{~min}^{-1}$ ). The screw profile was optimised to reduce glass fibre breaking during the process with an adopted extrusion process ( 2 zones of light mixing and a long pass-through zone).

Table 1. Composition of the different composites in terms of fibre amount.

\begin{tabular}{lcccc} 
Composites based on PP & $\begin{array}{c}\text { Commercial glass } \\
\text { fibres }(1)\end{array}$ & $\begin{array}{c}\text { Pure grinding process } \\
\left(\mathrm{SMC}^{\text {mod }}{ }^{1}\right)(2)\end{array}$ & $\begin{array}{c}\text { Mixed process } \\
\left(\mathrm{SMC}^{\text {mod }}{ }^{2}\right)(3)\end{array}$ & $\begin{array}{c}\text { T401 } \\
\text { (MCR) (4) }\end{array}$ \\
\hline Fillers amount $(\% \mathrm{wt})$ & 20 & 47 & 47 & 40 \\
Overall fibre amount $(\% \mathrm{wt})$ & 20 & 20 & 20 & 20
\end{tabular}
(1) PP20GF
(2) PP20GFsme ${ }^{\text {mod }}$ ।
(3) PP20GFsmc ${ }_{2}$
(4) PP20GF

The melted compounds were then chipped into pellet form after cooling. As in the extrusion step, the composites were dried ${ }^{[14]}$ for 3 days at $50^{\circ} \mathrm{C}$ prior to injection moulding for allowing polymer chains relaxation. Standard ISO 527-2 type 1A tensile test specimens were moulded using a $95 \mathrm{t}$ SANDRETTO AT injection system. 


\section{Mechanical properties of the composites :}

Tensile and Charpy impact tests were performed 3 days after injection moulding process ${ }^{[14]}$. Tensile tests were carried on using a ZWICK Z010 apparatus according to ISO 527 Standards to measure Young's modulus and yield stress. Charpy tests were investigated on un-notched standard specimens using a ZWICK 5101 (7 Joules) setup according to ISO 179 Standards.

\section{Results and discussion}

\section{Characteristics of fillers compounds :}

The SEM observation performed on $\mathrm{SMC}^{\bmod }{ }_{1}, \mathrm{SMC}_{2}^{\text {mod }}$ and $\mathrm{T} 401$ fractions showed that most of the glass fibres present have been well separated from the polyester matrix, in agreement with the results obtained by Allred et al. ${ }^{[1]}$. Nevertheless, as Kouparitsas et al ${ }^{[12]}$, can be still observed some aggregates containing polyester and fibres arranged in beams (Figures 2a). Calcium carbonate particles seemed to be present on the fibre surface (Figures 2b) which could provide anchorage sites to polypropylene chains.
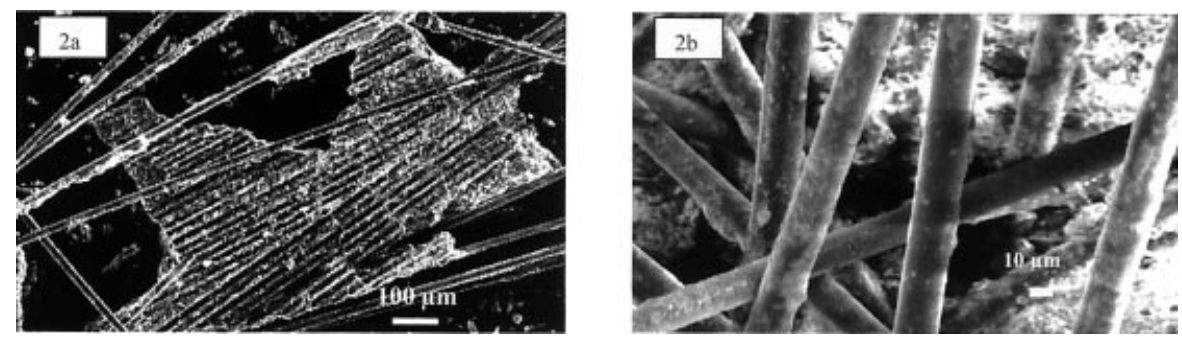

Figure 2. SEM images $x 100(2 a)$ and $x 500(2 b)$ of passing through ground $\mathrm{SMC}_{2}^{\bmod }$.

The compositions of initial SMC states and of $\mathrm{SMC}^{\bmod }{ }_{1}, \mathrm{SMC}^{\mathrm{mod}}{ }_{2}$ and $\mathrm{T} 401$ recycled fractions are presented on Table 2. It can be observed that the use of a mixed process increases the glass fibre content of about $47 \%$ compared to the pure grinding process. The high glass fibre content observed for T401 (42\%) is ascribed to the fact that this fraction is a mixture of pure glass fibre waste and SMC recycled fractions and that a sieving step was added in the process compared to our pure grinding process. Moreover, this additional step could have a negative effect on the global efficiency of the process which is about $60 \%$ compared to our processes that lead to higher efficiencies (70 and $90 \%$ ). SMC ${ }_{2}^{\text {mod }}{ }_{2}$ specimen seemed to show a greater amount of long fibres 
and smaller amounts of polyester and calcium carbonate particles. No significant differences are given in evidence between $\mathrm{T} 401$ and $\mathrm{SMC}^{\bmod }{ }_{1}$ fractions.

Table 2. SMC composition and efficiency according to the recycling process.

\begin{tabular}{lcccc} 
Composition (weight \%) & Initial SMC & Pure grinding $\left(\mathrm{SMC}^{\mathrm{mod}}{ }_{1}\right)$ & Mixed process $\left(\mathrm{SMC}^{\mathrm{mod}}{ }_{2}\right)$ & T401 (MCR) \\
\hline Unsaturated Polyester & $26.0 \pm 2.5$ & $22.7 \pm 2.5$ & $31.8 \pm 2.5$ & $22.0 \pm 2.5$ \\
Calcium carbonate & $52.0 \pm 2.5$ & $55.0 \pm 2.5$ & $25.6 \pm 2.5$ & $29.0 \pm 2.5$ \\
Glass fibre & $22.0 \pm 2.5$ & $22.3 \pm 2.5$ & $42.6 \pm 2.5$ & $42.0 \pm 2.5$ \\
Efficiency $(\%)$ & & 90 & 70 & 60
\end{tabular}

The glass fibre length distribution characteristics are shown on Table 3. $\mathrm{SMC}_{2}^{\bmod }$ clearly showed higher fibre length than $\mathrm{SMC}^{\text {mod }}{ }_{1}$ and $\mathrm{T} 401$. The fibre length is moreover too high to be analysed quantitatively by our image analysis procedure. Nevertheless it can be noticed this fibre length is comparable to that of the commercially available short glass fibres used for reinforcing thermoplastics. $\mathrm{SMC}^{\mathrm{mod}}{ }_{1}$ has an average fibre length comparable to that of $\mathrm{T} 401$, which has a smaller dispersity ; this is also enabled to the sieving operation.

Table 3. Glass fibre distribution according to the recycling process.

\begin{tabular}{lcccc} 
Distribution of glass fibre & Initial SMC & Pure grinding (SMC ${ }_{1}$ ) & Mixed process $\left(\mathrm{SMC}^{\text {mod }}{ }_{2}\right)$ & $\mathrm{T} 401(\mathrm{MCR})$ \\
\hline Average length $(\mathrm{mm})$ & $25-50$ & 0.62 & $2-10$ & 0.69 \\
Dispersity & - & 0.61 & - & 0.29
\end{tabular}

\section{Composites properties :}

The glass fibre length distributions were determined after compounding by extrusion. Table 4 results showed that the final length distribution obtained with $\mathrm{SMC}_{2}^{\text {mod }}{ }_{2}$ was similar to that obtained with commercial glass fibres and much higher than with T401. These preliminary data may indicate that the degradation rate of our recycled fibres fractions is not higher than those of standard short glass fibres; and these, despite of the fact that recycled fibres should no more brittle because of all the drastic conditions of grinding mechanical properties of the different composites are shown on Table 5. It can be observed that all mechanical properties (Young's modulus, yield stress and impact resistance) are decreased when recycling fibre fractions $\left(\mathrm{SMC}_{2}^{\mathrm{mod}}{ }_{2}\right.$ and $\left.\mathrm{T} 401\right)$ are used compared to commercial glass fibres. 
Table 4. Glass fibre length distribution after incorporation in PP matrix by extrusion process.

\begin{tabular}{|c|c|c|c|}
\hline Distribution of glass fibre in PP & Commercial glass fibres & Mixed process (SMC ${ }_{2}$ ) & T401 (MCR) \\
\hline Average length in number (mm) & 1.20 & 1.20 & 0.20 \\
\hline Average length in length $(\mathrm{mm})$ & 1.50 & 1.50 & 0.25 \\
\hline Dispersity & 0.21 & 0.21 & 0.29 \\
\hline $\begin{array}{l}\text { Critical length of glass fibres } \\
(\mathrm{mm}) \text { (according to Cox's model) }\end{array}$ & 0.60 & 0.60 & 0.60 \\
\hline
\end{tabular}

This result may be due to the presence of residual crosslinked polyester particles (about $14.9 \mathrm{wt} \%$ for PP20GFsmc ${ }_{2}^{\text {mod }}$ and $8.8 \mathrm{wt} \%$ for PP20GF $\mathrm{T}_{401}$ ) and of $\mathrm{CaCO}_{3}$ (about $12.0 \mathrm{wt} \%$ for PP20GFsmc ${ }_{2}^{\text {mod }}$ and $11.6 \mathrm{wt} \%$ for PP20GF $\mathrm{G}_{\mathrm{T} 401}$ ) within the composite material. These residues may be considered as impurities without any compatibility towards polypropylene chains that may increase the probability to cracks formation. Moreover these residues may modify the glass fibres orientation during injection moulding because of different melt viscosities and shear stresses. Finally, the lowered mechanical properties may be due, on the one hand to the brittleness of recycled fibres because of grinding conditions compared to standard short glass fibres, and on the other hand, to the lack of adhesion promotion on the recycled fibres surface. Next investigations would be to quantify the intrinsic mechanical properties of a recycled fibre and to analyse the recycled fibres surface though surface analysis techniques such as XPS (X ray Photoelectron Spectroscopy) and chemical extraction procedures ${ }^{[21]}$. Our alternative for better mechanical properties with recycled fibres fractions would be to improve the adhesion between the polypropylene matrix and the recycled fibres by introducing compatibilisation agents or by thermal or physical or chemical surface treatment. Table 5 showed also higher tensile properties for PP20GFsmc ${ }_{2}^{\text {mod }}{ }_{2}$ than for PP20GF ${ }_{\mathrm{T} 401}$ composite materials (as impact resistance kept constant with regards to standard deviations).

Table 5. Mechanical properties of different composite based PP matrix.

\begin{tabular}{lcccc}
\hline Mechanical properties & Virgin PP & PP20GF & PP20GFsme ${ }_{2}$ & PP20GF $_{\mathrm{T} 401}$ \\
\hline Tensile properties (Young's modulus) (MPa) & $1414 \pm 45$ & $5076 \pm 45$ & $4175 \pm 279$ & $3922^{\left[{ }^{81}\right.}$ \\
Yield stress (MPa) & $27.7 \pm 0.6$ & $57.6 \pm 0.4$ & $30.2 \pm 0.4$ & $25.8^{[8]}$ \\
Charpy resilience (non notched test pieces) $\left(\mathrm{kJ} / \mathrm{m}^{2}\right)$ & don't break & $18.4 \pm 1.9$ & $8.3 \pm 0.8$ & $10.3^{[8]}$
\end{tabular}

This result may be due to the very low fibre lengths measured after extrusion compounding for PP20GF $_{\mathrm{T} 401}(0.2 \mathrm{~mm})$ compared to PP20GFsmc ${ }_{2}^{\bmod }(1.2 \mathrm{~mm})$. This low fibre length should be 
the consequence of more brittle fibres after MCR recycling process so that a classical composite processing broke them easily. Nevertheless a such important variation in fibres length has also a non negligible effect on fibres orientation and dispersion and on the interfacial area between polymer and fibres, so that it remains delicate to conclude at the present moment.

\section{Conclusions}

A new efficient treatment process for obtaining filler compounds from SMC production waste has been described in this paper. Compared to existing processes involving only mechanical grinding, the addition of a dissolution step for calcium carbonate in our process allowed to obtain high glass fibre content in the final filler compound (about 43 wt \%) with a reasonable overall efficiency (70\%). This final composition was comparable to that obtained by industrial processes. Nevertheless, our process lead to higher glass fibre length in the compound, which are similar to those of fibres commercially available for introduction into thermoplastics. Nevertheless, the introduction of the obtained filler compound into a polypropylene matrix lead to a decreased in tensile and impact properties. Promising results should be expected taking into account the fact that the filler-matrix interface adhesion has not been optimised yet. This point will be the subject of a future paper.

[1] A.G. Pedroso, Progress in Rubber, Plastics and Recycling Technology, 2002, 18(2), 111.

[2] J.R. Kennerley, R.M. Kelly, Composites Part A, 1998, 29A, 839.

[3] S.J. Pickering, R.M. Kelly, Composites Science and Technology, 2000, 60, 509.

[4] Recycling takes off at MCR, Composites International, 2002, 48, 27.

[5] H. Winter, H.A.M. Mostert, Journal of Applied Polymer Science, 1995, 57(11), 1409.

[6] C.E. Bream, P.R. Homsby, Journal of Materials Science, 2001, 36, 2965.

[7] Thermosetting materials: recycling and applications, Composites (Paris), 1999, 35, 49.

[8] J.N. Reygrobellet, $P h D$ ihesis, University of Montpellier, France, 2000, 234 p.

[9] Recycling takes off at MCR, Composites International, 2002, 48, 27.

[10] C. Moncel, Recyclage Récupération Magazine, 2002, 16, 19.

[11] R.E. Allred, L.D. Busselle, Journal of Thermoplastic Composite Materials, 2000, 13, 92.

[12] C.E. Kouparitsas, C.N. Kartalis, Polymer Composites, 2002, 23(4), 682.

[13] L. Averous, $P h D$ thesis, University of Montpellier, France, 1995, $193 \mathrm{p}$.

[14] D.A. Steenkamer, J.L. Sullivan, Composite Part B, 1998, 29B, 745.

[15] R. von Turkovitch, L. Erwin, Polymer Engineering and Science, 1983, 23(13), 743.

[16] M.J. Carling, J.G. Williams, Polymer Composites, 1990, $111(6), 303$.

[17] F. Ulrych, M. Sova, Polymer Composites, 1993, /4(3), 229.

[18] V.B. Gupta, R.K. Mittal, Polymer Composites, 1989, 10(1), 8.

[19] V.R. Gupta, R.K. Mittal, Polymer Composites, 1989, 10(1), 16.

[20] J.L. Thomason, Composites Part A, 2002, A33, 1283.

[21] C.D. Papaspyrides, J. Poulakis, Polymer for Advanced Technologies, 1992, 3, 367. 